\title{
Desafios na Arte se Ensinar Inclusiva: A Relação Professor e Intérprete na Inclusão do Surdo
}

Simone Erbs da Costa, UDESC, simoneerbsdacosta@gmail.com Indianara A. de Souza, UDESC, indianara.amancio@gmail.com Délio Delcio Augusto Hofelmann, UDESC, deliodh@gmail.com Fabiola Sucupira Ferreira Sell, UDESC,fabiola.sell@udesc.br Carla Diacui Medeiros Berkenbrock, UDESC, carla.berkenbrock@udesc.br

\begin{abstract}
Resumo. O presente artigo tem como objetivo discutir os obstáculos que o aluno surdo enfrenta nos espaços educacionais, bem como compreender as dificuldades existentes na interação entre professor e intérprete nesses ambientes. Um novo olhar nesse cenário se faz necessário assim como transformações na forma em que os conteúdos são apresentados e nas relações entre surdo, escola e educadores. Nessa pesquisa são analisadas as contribuições das Tecnologias de Informação e Comunicação (TIC) para apoiar a aprendizagem dos alunos surdos. A partir das pesquisas realizadas na literatura e dos dados coletados em entrevistas e questionários com professores e intérpretes também são sugeridas ações e posturas destinadas aos educadores.
\end{abstract}

Palavras chaves: inclusão social; educação inclusiva; aluno surdo; ambiente acadêmico; educador; intérprete.

Challenges in Art if Inclusive Teaching: The Teacher and Interpreter relationship in the inclusion of the deaf

\begin{abstract}
This article aims to discuss the obstacles that deaf student faces in educational activities, as well as understand the difficulties in the interaction among teacher and interpreter in these environments. A new look in this scenario is necessary, additionally to changes in the way that content is presented and in relations among deaf, school and educators. This research analyzes the contribution of Information and Communication Technologies (ICT) to support learning of the deaf students. From the research in the literature and data collected in interviews and questionnaires with teachers and interpreters we also suggest actions and attitudes to the educators.
\end{abstract}

Keywords: social inclusion; inclusion education; deaf student; academic environment; educator; interpreter.

\section{Introdução}

Muito se fala em igualdade nos dias de hoje. Aristóteles, desde a época de Platão já colocava que devemos tratar igualmente os iguais e desigualmente os desiguais na medida de suas desigualdades [De Aquino et al. 2001]. Esse pensamento do filósofo enfatiza que as pessoas precisam ser tratadas de forma igual, dentro das suas capacidades. Estendendo esse pensamento para as salas de aula, trabalhar as desigualdades existentes faz parte do processo de inclusão, sendo algo benéfico.

Vivemos num país com diferenças culturais, econômicas e sociais. O acesso a educação e a tecnologia ainda é precário [Brasil 2001]. Segundo [IBGE 2010], no censo 
de 2009 foram registradas $23,9 \%$ da população brasileira com algum tipo de deficiência e 5,1\% com algum tipo de Deficiência Auditiva (DA). Conforme [Falcão and Price 2012], os alunos com necessidades especiais aprendem mais quando inseridos nas classes regulares, pois geralmente são agrupados para receber apoio extra nas aulas. Assim como, [Tenor and Deliberato 2015], entendem que o aluno surdo deve frequentar a escola regular participando das atividades normais previstas e que o professor deve prover adaptações a fim de garantir o aprendizado de forma efetiva. Em contrapartida, [Nogueira 1997], coloca que a escola especial para surdos, devidamente sinalizada, seria um ambiente onde as crianças viveriam satisfatoriamente e na fase adulta estariam preparadas para conviver no mundo dos ouvintes.

Nesse contexto, existem dois cenários: um que trata da educação inclusiva e outro que trata da educação bilíngue. A pesquisa em questão tem como objetivo propor ações e posturas para o professor e intérprete para a educação inclusiva de alunos surdos. Além disso, este trabalho apresenta formas de utilizar ferramentas de Tecnologia da Informação e Comunicação (TIC) para auxiliar o surdo, os educadores e a escola, propiciando um ambiente inclusivo. Para tal, foi realizada uma pesquisa quáli-quantitativa com intérpretes de Libras e professores do estado de Santa Catarina que tiveram em suas experiências curriculares alunos surdos. Nessa pesquisa, buscou-se a identificação das dificuldades existentes na inclusão com foco na relação entre educadores, professor e intérprete.

O presente trabalho está organizado da forma que segue. A seção 2 contêm reflexões sobre os educadores e a cultura do surdo. A seção 3 apresenta a metodologia utilizada na pesquisa. A seção 4 trata dos 3 instrumentos utilizados, as pesquisas realizadas na literatura e as experiências dos educadores. A seção 5 contém uma discussão com base na pesquisa quali-quantitativa realizada, propondo ações e posturas de forma colaborativa e o uso de TICs. E por fim, a seção 6 apresenta as conclusões resultantes da pesquisa e a continuidade da mesma.

\section{Educadores e a Cultura Surda}

A educação dos surdos é um cenário desafiador e inspirador. De acordo com [Tenor and Deliberato 2015] é visível que o processo de inclusão do aluno surdo não depende apenas das ações do professor em sala de aula e sim, demandam da troca de saberes entre todos os profissionais envolvidos. Neste cenário, pode-se fazer uso das ferramentas TIC. Conforme [dos Santos and Favero 2014], na educação inclusiva dos surdos, os recursos tecnológicos aliados com estratégias educativas adequadas fomentam o aprender de forma interativa, uma vez que é necessário reconhecer as potencialidades da tecnologia e tomar consciência da realidade em que a escola está inserida, evitando assim, a mera informatização do ensino

Uma pessoa é considerada com deficiência auditiva se houver "[..] perda bilateral, parcial ou total, de quarenta e um decibéis $(\mathrm{dB})$ ou mais, aferida por audiograma nas frequências de $500 \mathrm{~Hz}, 1.000 \mathrm{~Hz}, 2.000 \mathrm{~Hz}$ e $3.000 \mathrm{~Hz}$ ", conforme [BRASIL 2005], em seu parágrafo único do art. $\mathrm{n}^{\mathrm{o}} 20$ do decreto $\mathrm{n}^{0}$ 5.626. No art. $\mathrm{n}^{\mathrm{o}} 20$ do mesmo decreto é considerada surda "[...] aquela que, por ter perda auditiva, compreende e interage com o mundo por meio de experiências visuais, manifestando sua cultura principalmente pelo uso [...] Libras"[BRASIL 2005]. A Constituição Federal Brasileira de 1988 garante o direito de acesso e a educação pública para todos e sua legislação foi se aperfeiçoando no decorrer dos anos. De acordo com [BRASIL 2002], em 24 de abril de 2002 pela Lei ${ }^{\circ}$ 10.436 no seu parágrafo único do art. $\mathrm{n}^{\circ} 10$ Libras foi reconhecida como uma forma de 
comunicação legal:

Art. 10. Libras como forma de comunicação legal:

Parágrafo único. Entende-se como Língua Brasileira de Sinais - Libras a forma de comunicação e expressão, em que o sistema linguístico de natureza visual-motora, com estrutura gramatical própria, constituem um sistema linguístico de transmissão de ideias e fatos, oriundos de comunidades de pessoas surdas do Brasil.

De acordo [BRASIL 2005], o objetivo de garantir o acesso a todos à educação, o decreto $\mathrm{n}^{\circ} 5.626$ de dezembro de 2005 dispõe do art. $\mathrm{n}^{\circ} 14$ que:

Art. 14. Objetivo de garantir o acesso a todos à educação:

As instituições federais de ensino devem garantir, obrigatoriamente, às pessoas surdas acesso à comunicação, à informação e à educação nos processos seletivos, nas atividades e nos conteúdos curriculares desenvolvidos em todos os níveis, etapas e modalidades de educação, desde a educação infantil até à superior.

Já o intérprete de línguas tem sua profissão reconhecida pelo projeto de lei $\mathrm{n}^{\mathrm{o}}$ 12.319, de 1 de setembro de 2010 conforme [BRASIL 2005], no parágrafo único do art. $\mathrm{n}^{\mathrm{o}} 2$, uma de suas atribuições consta no Inciso II do art. $\mathrm{n}^{\mathrm{o}} 6$ :

Art 6. Uma das atribuições do intérprete:

II - Interpretar, em Língua Brasileira de Sinais - Língua Portuguesa, as atividades didático-pedagógicas e culturais desenvolvidas nas instituições de ensino nos níveis fundamental, médio, e superior, de forma a viabilizar o acesso aos conteúdos curriculares.

O aprendizado do aluno surdo é influenciado por vários fatores conforme observa [Brito and de Jesus Ferreira 2013], sendo Libras um elemento fundamental para o aprendizado. Conforme assegura a lei, todo aluno surdo tem direito a ter um intérprete de Libras em sala de aula, assim como material de apoio. Em sala de aula, conforme [Martins 2004], a responsabilidade de ensinar é do professor da classe de aula e não do intérprete, mesmo que o intérprete tenha algum tipo de formação no que estiver traduzindo.

De acordo com [Bulgraen 2010], no processo de aprendizagem deve ser levado em consideração a questão social do aluno, de forma que o professor resgate aspectos culturais do surdo. Desta forma, o aluno pode contextualizar suas experiências e aprendizados na vida social. As TICs possibilitam a redução de barreiras e podem ser vistas como pontes nas relações sociais, constituindo uma oportunidade, superando barreiras e desta forma, reduzindo seu isolamento social. Ideia fundamentada por [Montoya 2000], que constata que as barreiras podem ser vistas como oportunidades para o acesso à informação, à comunicação e à aprendizagem.

A autora [Strobel 2009] insere a comunidade surda dentro de uma nova cultura: a cultura surda, definida por uma identidade. A identidade, pela forma que o indivíduo surdo entende o mundo a sua volta e é capaz de modificá-lo com as suas percepções visuais tornando-o acessível e habitável; e a linguagem por sua forma de comunicação com o mundo a sua volta. Para [Strobel 2009], a cultura surda vai além dessas propriedades, trazendo ideias, crenças, costumes e hábitos próprios, fortalecendo mais ainda a identidade da cultura surda.

Fornecer uma educação inclusiva não pode ser considerado um processo tranquilo de integração de diferenças, mas um espaço de lutas [Klein and Lunardi 2008]. Além disso, [Coelho et al. 2011], observa que existe uma nova forma da compreensão do processo educacional, da aprendizagem, passando a privilegiar uma cultura do conhecimento. 
Dentro desse cenário, também precisam ser levados em consideração os conceitos preexistentes na estrutura cógnito-afetiva dos sujeitos. Ainda na direção da realidade nem sempre positiva da inclusão conforme observa [Spenassato and Giareta 2009], que em algumas escolas, o conteúdo é transmitido pelos docentes numa perspectiva tradicional, sem levar em consideração as limitações físicas, intelectuais ou linguísticas de seus alunos. Desta forma, transmitem um ensino desarticulado da realidade dos alunos, fazendo com que os mesmos não tenham uma aprendizagem significativa. $\mathrm{O}$ despreparo dos professores para o ensino nessa diversidade é um grave problema, que podem gerar equívocos educacionais [Borges et al. 2013].

Em meio a esse cenário, entre a utopia da inclusão e das escolas brasileiras, está o surdo que historicamente não era acreditado enquanto capaz de aprender, mas que no decorrer dos anos foi conquistando o direito de acesso aos conhecimentos e ganhando espaço dentre as reflexões no âmbito educacional [Guarinello 2007].

\section{Metodologia}

Nesta pesquisa, primeiramente se buscou na literatura fontes que conceituassem o papel do professor, do intérprete, suas relações e a educação inclusiva, com foco nos alunos surdos. Foram realizadas duas entrevistas do tipo não estruturadas, a fim de identificar dificuldades no processo de inclusão. A partir dos dados coletados na entrevista foi elaborado um questionário para os educadores, com questões de múltipla escolha e dissertativas. O intuito do questionário foi obter relatos das experiências vivenciadas, a fim de investigar os problemas na relação estabelecida entre os educadores e as deficiências no processo de inclusão do aluno surdo. Os dados são mostrados na forma de gráfico e podem ser vistos na seção 4. Esses dados foram analisados de duas formas: os de natureza quantitativa por distribuição de frequência e os qualitativos por meio da análise de conteúdo de Bardin [Bardin 1977], utilizando os quatro polos cronológicos - pré-análise, exploração do material, apresentação dos mesmos e tratamento dos dados.

Considerando o método de análise de conteúdo de Bardin [Bardin 1977], na préanálise foi realizada uma leitura flutuante de todas as respostas obtidas pelo questionário e de todas as anotações realizadas das entrevistas não estruturadas. Após essa leitura foi possível ter uma primeira impressão do material coletado e estabelecer algumas hipóteses. A exploração do material foi a etapa seguinte, onde os dados coletados no questionário foram categorizados seguindo a técnica de análise de categoria. De acordo com [Bardin 1977], essa técnica consiste em operações de desmembramento do texto em categorias segundo reagrupamentos. Na terceira etapa foram apresentados os dados coletados pelo questionário quáli-quantitativo em forma de gráficos. As categorias estabelecidas na etapa de exploração do material foram delineadas considerando a frequência e o contexto em que apareceram nas respostas do questionário. Por último, a partir dos resultados obtidos foram traçadas algumas ações e posturas direcionadas ao professor e ao intérprete para apoiar a educação inclusiva dos alunos surdos, apresentadas na seção 5. Além dessas discussões, foram sugeridas formas de utilização de ferramentas TIC para apoiar a educação inclusiva de forma colaborativa.

\section{Pesquisa: Os Relatos da Experiência}

Participaram da pesquisa 40 educadores. $\mathrm{O}$ instrumento de entrevista foi aplicado com 2 educadores, onde um é professor e o outro intérprete. Já o instrumento de questionário foi aplicado com 38 educadores, sendo 27 professores $(71,1 \%)$ e 11 intérpretes $(28,9 \%)$, 
conforme Figura 1. Relacionado as modalidades de ensino trabalhadas pelo educador com alunos surdos, 3 deles responderam que trabalham com alunos de pós graduação (7,9\%), 11 deles trabalham com alunos do ensino superior (28,9\%), 20 deles trabalham com alunos do ensino técnico (52,6\%), 16 deles trabalham com educação básica $(42,1 \%)$ e 8 deles trabalham com modalidades diferentes das citadas $(21,1 \%)$, conforme Figura 2. Referente aos anos de experiência com educação, nenhum dos educadores respondeu que trabalha a menos de 1 ano (0\%), 6 deles entre 1 e 3 anos $(15,8 \%)$ de experiência, 5 deles possuem de 3 a 5 anos $(13,2 \%)$ de experiência e 27 responderam que possuem mais do que 5 anos $(71,1 \%)$ de experiência, conforme Figura 3.

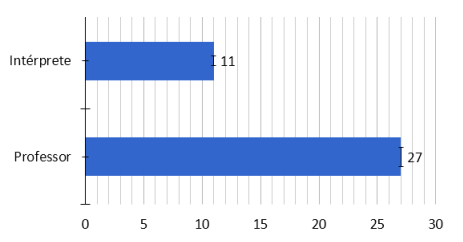

Figura 1. Educadores

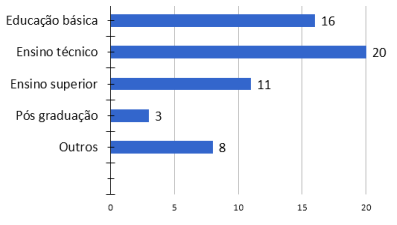

Figura 2. Modalidades de ensino

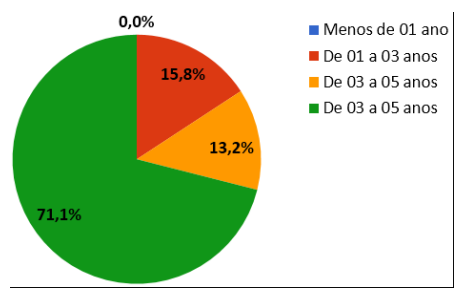

Figura 3. Tempo no ensino

Ao serem questionados se existe uma preparação individual do educador (professor ou intérprete) antes do início das aulas para estarem preparados para receberem o aluno surdo, 13 deles responderam que $\operatorname{sim}(34,2 \%)$ e 25 deles responderam que não $(65,8 \%)$, conforme Figura 4. Em relação a existência de uma preparação em conjunto entre professor e intérprete antes do início das aulas, 13 deles responderam que $\operatorname{sim}(34,2 \%)$ e 25 deles responderam que não $(65,8 \%)$, conforme Figura 5. Sobre o material fornecido para o surdo ser diferenciado, como: provas, trabalhos e apostilas, 14 responderam que não $(68,4 \%)$ e 5 responderam que sim $(38,4 \%)$, conforme Figura 6.

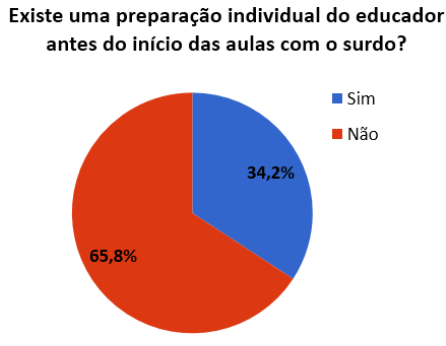

Figura 4. Preparação individual

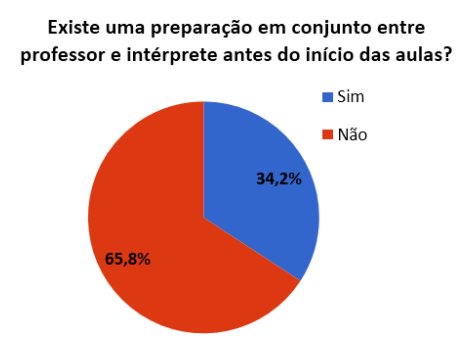

Figura 5. Preparação conjunta

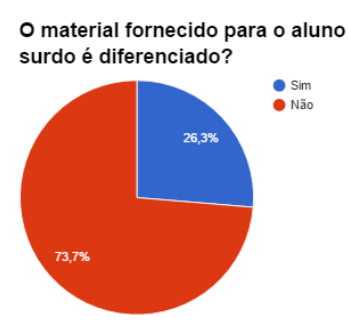

Figura 6. Material diferenciado

Dos 38 educadores que responderam ao questionário, relacionado com o preparo de material, 9 deles responderam que utilizam recursos visuais $(21,4 \%), 8$ utilizam linguagem objetiva (19\%), 6 usam texto direcionado (14,3\%) e 6 usam material legendado $(14,3 \%)$. No que diz respeito a importância de conhecer o material, 3 deles comentaram que é importante ter conhecimento do conteúdo $(7,1 \%), 1$ deles que utiliza escrita de sinais e 4 deles não utilizam material adaptado (9,5\%), conforme Figura 7. A troca de informações também foi identificada entre os educadores, 3 responderam que existe a troca de informações por uma breve conversa (12\%), 1 que a conversa é relacionada com o plano de aula (4\%), 15 que existe a troca de informações mas não especificaram de que forma (60\%), 3 colocam que ocorre antes das atividades (12\%) e 3 que não existe troca de informações (12\%), conforme Figura 8. Foi possível identificar dentre esses educadores 
a forma que as avaliações são realizadas ao ter um aluno surdo. Não existe adaptação no sentido da forma e não de conteúdo. Foi possível observar que 8 educadores procuram adaptar as provas (72,7\%), 2 mencionaram que não ocorre o preparo de avaliações diferenciadas, mas as correções são adequadas a forma linguística que o aluno surdo aprende $(18,2 \%)$ e 1 comentou que existe uma forma de avaliação, mas não especificou como ela ocorre $(9,1 \%)$, como mostra a Figura 9.

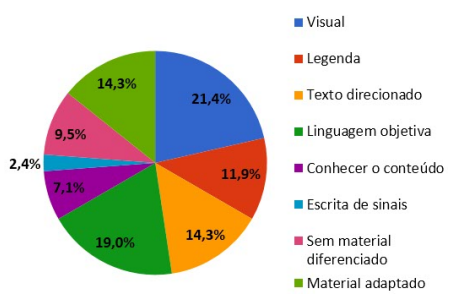

Figura 7. Preparo do material

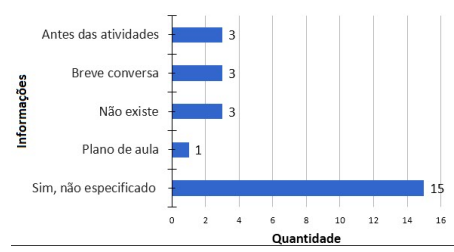

Figura 8. Troca de informações

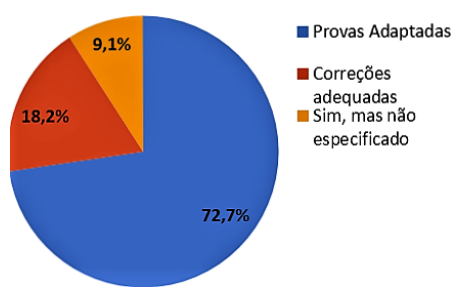

Figura 9. Avaliação diferenciada

$\mathrm{Na}$ categoria compartilhamento de materiais, 4 educadores mencionaram que o compartilhamento existe por meio das ferramentas TIC (44,4\%). Já outros 4 educadores que ela existe mas não especificaram de qual forma acontece $(44,4 \%)$ e um 1 educador especifica que compartilha o material por e-mail $(11,1 \%)$, conforme mostra a Figura 10. Referente a preocupação com o aprendizado para com o aluno surdo, apresentado na Figura 11, dos 38 educadores que responderam ao questionário, 5 demonstraram preocupação com o aprendizado do aluno surdo (41,7\%), 1 mencionou que o aprendizado do aluno surdo está relacionado com a sua formação nos anos iniciais (8,3\%). A cumplicidade entre os educadores foi mencionada por 2 deles $(16,7 \%), 1$ mencionou que faz atividades diferenciadas $(8,3 \%)$ e 1 mencionou a necessidade de se ter um intérprete $(8,3 \%)$. Outro ponto levantado por 1 educador é o fato do feedback ser inadequado $(8,3 \%)$ e 1 deles colocou que é necessário ter uma boa interpretação $(8,3 \%)$. No que diz respeito ao comportamental, mostrado na Figura 12, 3 dos educadores mencionaram a importância do conhecimento da cultura surda (30\%), 2 deles que buscam promover a socialização do aluno surdo (20\%) e 2 procuram adaptar-se as necessidades do aluno surdo (20\%). Ainda, 1 educador mencionou a importância da colaboração (10\%), outro mencionou que começou a falar mais devagar (10\%) e um terceiro mencionou sobre alguns professores sentirem-se incomodados com a presença do intérprete e aluno surdo (10\%).

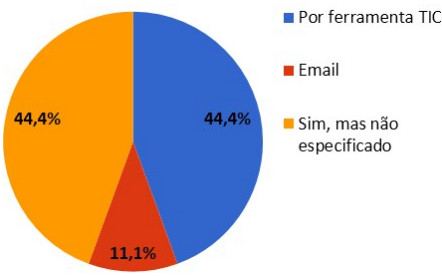

Figura 10. Compartilhamento

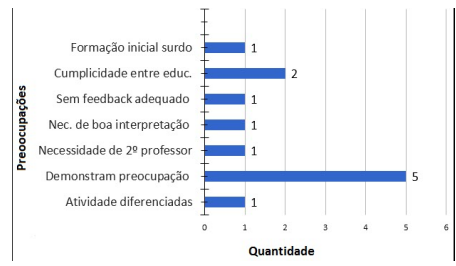

Figura 11. Aprendizado

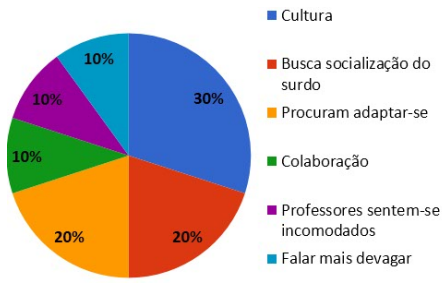

Figura 12. Comportamento

Alguns educadores utilizam uma comunicação específica e seus dados podem ser observados na Figura 13. A comunicação por Libras foi um ponto levantado por 1 dos educadores (10\%), 1 mencionou a leitura labial pelo aluno surdo (10\%), 2 dos educadores utilizam escrita sinalizada (20\%), 1 educador mencionou que os alunos regulares buscaram a comunicação por Libras com o aluno surdo(10\%), o próprio aluno surdo ensinou. 
A prática de escrever no quadro em mais de uma situação foi utilizada por 1 educador $(10 \%)$ e 3 educadores mencionaram a necessidade dos envolvidos no processo de inclusão conhecerem Libras (30\%). Também foi possível identificar o relacionamento entre os educadores. Esse foi um ponto que 1 educador comentou que faz diferença quando existe um bom relacionamento entre os educadores $(16,7 \%)$ e 2 dos educadores comentaram que ela deveria existir $(33,3 \%)$. Atividades de plano de aula é comentado por 1 educador $(16,7 \%)$, troca de ideias é comentado por outro educador $(16,7 \%)$ e por um terceiro educador que existe o relacionamento entre os educadores relacionado com o planejamento das atividades, conforme mostra a Figura 14. Por fim, foi identificada a categoria TIC, que relaciona a menção ao uso de ferramentas de tecnologia da comunicação e informação no processo de inclusão. Foi observado por 3 educadores que o e-mail é utilizado para o compartilhamento de materiais $(23,1 \%), 2$ utilizam para trabalhar com imagens $(15,4 \%)$, 2 utilizam para o preparo de material legendado $(15,4 \%)$. Além disso, 2 utilizam para adaptar seu material $(15,4 \%)$, 1 utiliza para fazer slides $(7,7 \%)$ e 1 educador comentou que utiliza tablet em suas atividades $(7,7 \%)$, conforme a Figura 15.

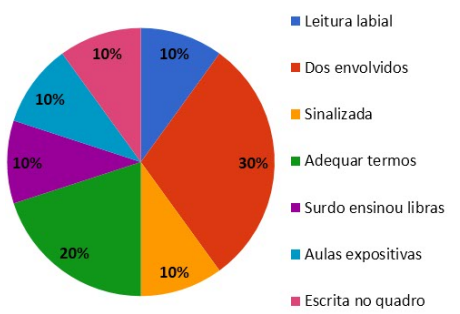

Figura 13. Comunicação

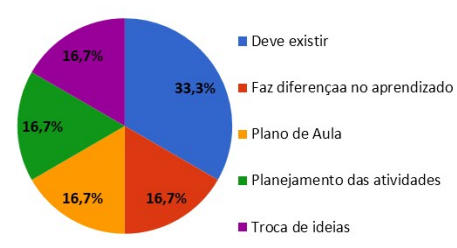

Figura 14. Relação entre educadores

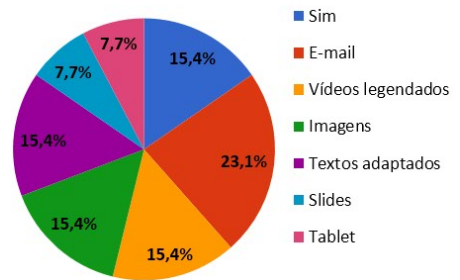

Figura 15. Uso de ferramentas TICs

\section{Discussões}

Esta seção visa propor ações e posturas a serem observadas pelo professor e pelo intérprete, assim como, formas de utilização de ferramentas TIC para apoiar o processo de inclusão social na educação. As recomendações indicadas nos quadros apresentados a seguir foram obtidos por meio dos dados coletados pelos instrumentos apresentados nas seções 2 e 4, conforme a metodologia apresentada na seção 3.

A troca de informações entre os educadores é fundamental, no entanto, como observado nesta pesquisa nem sempre ela ocorre. O Quadro 1 trata a relação professor e intérprete, propondo ações e atitudes a serem tomadas pelos educadores para uma inclusão mais efetiva.

A inclusão social deve considerar que os surdos possuem particularidades. Incluir alunos surdos em uma classe regular é um processo mais complexo que simplesmente incluir um intérprete para realizar a tradução. No Quadro 2 pode ser observado algumas das responsabilidades que os envolvidos devem possuir no processo de inclusão. 
Quadro 1. Ações e Atitudes a serem tomadas pelos Professores e Intérpretes

Os educadores devem manter uma relação de diálogo e troca de informações, para facilitar a inclusão do aluno surdo.

Mediante o mantenimento de um canal de comunicação entre os educadores, esses devem ajudarem-se nos aspectos que devem ser observados e adaptados ao surdo. Como por exemplo, a adaptação das atividades e posturas, para uma melhor inclusão.

O professor deve disponibilizar seu material ao intérprete e auxiliá-lo em suas dúvidas; assim como, o intérprete deve buscar o conhecimento prévio do conteúdo a ser trabalhado em sala de aula pelo professor. Dessa forma, buscando uma sinalização adequada aos termos técnicos e demais especificidades.

Em sala de aula, o professor deve ministrar a aula para todos os alunos, não esquecendo que o intérprete estará presente para apoiá-lo no que diz respeito a tradução mas a responsabilidade sobre passar o conteúdo é do professor. Da mesma forma, o intérprete deve fazer a interpretação de forma imparcial e fiel ao conteúdo.

O professor deve sempre explicar o conteúdo voltado de frente para os alunos, nunca de costas. Alguns alunos surdos fazem leitura labial, o que facilita seu entendimento. Esse tipo de orientação pode ser realizada ao professor pela pedagoga da instituição, caso exista, ou pelo intérprete.

O intérprete deve posicionar-se em um local adequado em sala de aula para realizar sua interpretação. Definido este local, o professor também deve respeitá-lo, não passando na frente do intérprete no momento da interpretação.

Quadro 2. Envolvidos e suas Responsabilidades

\begin{tabular}{|l|l|}
\hline Envolvidos & Responsabilidades \\
\hline Professor & $\begin{array}{l}\text { Compreender seu papel em sala. } \\
\text { Compreender o papel do intérprete em sala, respeitando-o. } \\
\text { Ter conhecimento básico em Libras para comunicação básica. } \\
\text { Não delegar as responsabilidades pelo aprendizado ao intérprete. } \\
\text { Adaptar seus materiais, atitudes e condutas as necessidades do aluno. }\end{array}$ \\
\hline Intérprete & $\begin{array}{l}\text { Compreender seu papel em sala. } \\
\text { Compreender o papel do professor, respeitando-o e auxiliando-o. } \\
\text { Não delegar suas responsabilidades ao outro. } \\
\text { Adaptar seus materiais de forma colaborativa, atitudes e condutas as } \\
\text { necessidades do aluno surdo. }\end{array}$ \\
\hline & $\begin{array}{l}\text { Inserir o estudante surdo em uma classe regular. } \\
\text { Adaptar o modo de ensino ao aluno surdo. } \\
\text { Propiciar aos educadores capacitações para que possam adaptar-se a re- } \\
\text { alidade do aluno surdo e acolhê-lo melhor. } \\
\text { Fornecer aulas de reforço com intérprete ao aluno surdo, visto que seu } \\
\text { ritmo de aprendizado normalmente é diferenciado. }\end{array}$ \\
\hline
\end{tabular}


A cultura dos surdos deve ser levada em consideração no processo de inclusão. Conforme visto em [Strobel 2009], é necessário fornecer uma educação inclusiva que fortaleza a cultura dos surdos. O Quadro 3 aborda esses aspectos, assim como contêm sugestões de tratativas para tais aspectos.

\section{Quadro 3. Aspectos Culturais do Surdo e Tratativas}

\begin{tabular}{|l|l|}
\hline Aspectos culturais & Tratativas \\
\hline $\begin{array}{l}\text { Leitura fragmentada: o surdo lê pa- } \\
\text { lavra por palavra, tendo dificuldade } \\
\text { em uni-las e formar um conceito. }\end{array}$ & $\begin{array}{l}\text { Os educadores devem considerar esse aspecto, } \\
\text { adaptando seus textos para uma linguagem mais } \\
\text { direta e simplificada. O material deve ser elabo- } \\
\text { rado de forma colaborativa entre educadores. }\end{array}$ \\
\hline $\begin{array}{l}\text { Formação anterior: muitos alunos } \\
\text { surdos possuem deficiências acadê- } \\
\text { micas oriundas de sua formação an- } \\
\text { terior precária. Algumas vezes, o } \\
\text { surdo nunca teve intérprete em sala } \\
\text { de aula. }\end{array}$ & $\begin{array}{l}\text { como se deu o processo de alfabetização e seu } \\
\text { histórico acadêmico. De pos educadores e a escola conseguem tra- } \\
\text { çar melhores estratégias no ensino dos alunos } \\
\text { de forma colaborativa. }\end{array}$ \\
\hline $\begin{array}{l}\text { Visão espacial: tendo um sentido a } \\
\text { menos, o da audição, o surdo possui } \\
\text { uma visão espacial apurada. Carac- } \\
\text { terística não presente em todos os } \\
\text { ouvintes. }\end{array}$ & $\begin{array}{l}\text { Os educadores considerando esse aspecto de- } \\
\text { vem adaptar seus materiais e a forma de en- } \\
\text { sino utilizando-se de recursos visuais para me- } \\
\text { lhor ilustrarem os conceitos ao aluno. O uso de } \\
\text { metáforas e analogias nem sempre é eficaz ao } \\
\text { surdo. }\end{array}$ \\
\hline
\end{tabular}

As ferramentas TIC devem ser usadas como uma forma de transpor algumas das muitas barreiras existentes na inclusão social. Conforme observa [Montoya 2000], as barreiras podem ser vistas como oportunidades para o acesso à informação, à comunicação e à aprendizagem. O Quadro 4 apresenta exemplos de ferramentas TIC e sua utilização no apoio a inclusão.

Quadro 4. Utilização de Ferramentas TIC

\begin{tabular}{|l|l|}
\hline Ferramenta & Utilização \\
\hline Google Drive, Dropbox & Compartilhamento de materiais entre educadores e alunos. \\
\hline Youtube & Para melhor ilustrar os conceitos, por meio de vídeos. \\
\hline VisualPedia & $\begin{array}{l}\text { Preparo de materiais de forma colaborativa, com simplifica- } \\
\text { ção textual. }\end{array}$ \\
\hline PowerPoint, Prezi & Para preparo de materiais com características visuais. \\
\hline Projetor & $\begin{array}{l}\text { Equipamento como alternativa ao quadro e giz, para expo- } \\
\text { sição de conteúdos e exemplificações. }\end{array}$ \\
\hline
\end{tabular}

\section{Conclusões e Trabalhos Futuros}

No presente trabalho são sugeridas ações e posturas para os professores, intérpretes, assim como para a instituição de ensino; visando uma educação inclusiva do aluno surdo de fato. Todos os envolvidos no processo: educadores, escola, colegas de classe e os alunos surdos tem sua parcela de responsabilidade no processo inclusivo. É importante que todos tenham conhecimento dos aspectos culturais do aluno surdo para que o mesmo não permaneça num estado de invisibilidade.

V. $14 \mathrm{~N}^{\mathrm{o}}$ 2, dezembro, 2016 
Outro ponto identificado neste artigo é a forma como ocorre a comunicação do aluno surdo com os envolvidos no processo de aprendizagem. Para que o aluno surdo esteja inserido na sua totalidade, o professor tem que estar ciente de que precisa ter um conhecimento básico de Libras para se comunicar diretamente com seu aluno. Os colegas de classe precisam ter a mesma capacidade para que exista ao menos uma comunicação corriqueira. Além disso, a instituição tem que estar preparada para receber o aluno surdo desde quando ele chega na escola, ou seja, a começar da portaria da instituição até a sala de aula. Outro ponto importante é a relação entre os educadores que nem sempre ocorre da maneira desejada.

Se de fato queremos uma inclusão social e não um inclusão perversa precisamos estar atentos as formas e maneiras que se pode trabalhar no ensino-aprendizagem do surdo: tanto na educação inclusiva como na educação bilíngue. Diante desse cenário, questionamos as instituições, professores, intérpretes e o próprio governo: queremos de fato uma sociedade inclusiva?

Como trabalhos futuros, pretende-se desenvolver um sistema para apoiar a colaboração entre os professores e intérpretes, assim como promover uma maior interação do aluno surdo no processo de aprendizagem.

\section{Referências}

Bardin, L. (1977). Análise de conteúdo. Edições 70.

Borges, A. C., Oliveira, E. C. B., Pereira, E. F. B., and Oliveira, M. D. d. (2013). Reflexões sobre a inclusão, a diversidade, o currículo e a formação de professores. In Anais Eletrônicos do Congresso Acadêmico Científico da UEG de Porangatu.

Brasil (2001). As licenciaturas nos centros federais de educação tecnológica.

BRASIL (2002?). Lei de libras - lei 10436/02 - lei no 10.436, de 24 de abril de 2002.

BRASIL (2005). Decreto 5626/05 - decreto $\mathrm{n}^{\circ}$ 5.626, de 22 de dezembro de 2005.

Brito, B. P. and de Jesus Ferreira, B. (2013). Proposta de uma ferramenta de reforço de vocabulário na educação de surdos. RENOTE, 13(1).

Bulgraen, V. C. (2010). O papel do professor e sua mediação nos processos de elaboração do conhecimento. Revista Conteúdo, Capivari, 1(4):30-38.

Coelho, C. M., Raposo, P. N., da Silva, E., and de Almeida, A. C. F. (2011). Acessibilidade para pessoas com deficiência visual no moodle. Linhas Críticas, 17(33):327-348.

De Aquino, T., Mallea, A., and Mendoza, C. A. L. (2001). Comentario a la Ética a Nicómaco de Aristóteles. Ediciones Universidad de Navarra, SA.

dos Santos, M. A. R. and Favero, E. L. (2014). Mchq-alfa: Uma proposta de ferramenta para aprendizagem da língua portuguesa na educação de surdos utilizando o potencial das histórias em quadrinhos mediada por mapa conceitual. RENOTE, 12(1).

Falcão, T. P. and Price, S. (2012). Tangibles for students with intellectual disabilities. In 11th Intern. Conference on Interaction Design and Children, pages 371-374. ACM.

Guarinello, A. C. (2007). O papel do outro na escrita de sujeitos surdos. Plexus Editora.

IBGE (2010). Censo demográfico 2010 - resultados gerais da amostra.

Klein, M. K. and Lunardi, M. L. (2008). Surdez: um território de fronteiras deafness: a territory of boundaries. ETD - Educação Temática Digital, 7(2):14-23.

V. $14 \mathrm{~N}^{\mathrm{o}} 2$, dezembro, 2016 
Martins, V. d. O. (2004). Intérprete ou professor: o papel do intérprete de língua de sinais na educação inclusiva de alunos surdos. 2004. TCC de Pedagogia em Educação Especial-Faculdade de Educação da Pontifícia Universidade Católica de Campinas.

Montoya, R. S. (2000). Integración holística de la tecnología adaptativa. Cádiz: Universidad de Cádiz.

Nogueira, M. d. A. M. (1997). Interação professor-ouvinte e pré-escolares surdos em duas alternativas metodológicas. CORDE.

Spenassato, D. and Giareta, M. K. (2009). Inclusão de alunos surdos no ensino regular: investigação das propostas didático-metodológicas desenvolvidas por professores de matemática no ensino médio da eenav. EENAV.

Strobel, K. L. (2009). As imagens do outro sobre a cultura surda. Ed. da UFSC.

Tenor, A. C. and Deliberato, D. (2015). Sistematização de um programa de capacitação ao professor do aluno surdo. Rev. bras. educ. espec, 21(3):409-422. 